\title{
A COMPREHENSIVE 2-D DIVERTOR DATA SET FROM DIII-D FOR EDGE THEORY VALIDATION
}

\author{
by \\ M.E. Fenstermacher, ${ }^{\dagger}$ S.L. Allen, ${ }^{\dagger}$ D.N. Hill, ${ }^{\dagger}$ A.W. Leonard ,C.J. Lasnier, ${ }^{\dagger}$ T.W. Petrie, \\ R.D. Wood, ${ }^{\dagger}$ N.H. Brooks, D.A. Buchenauer, $¥$ T.N. Carlstrom, J.W. Cuthbertson, $\diamond$ \\ E.J. Doyle, $\Delta$ T.E. Evans, P.-M. Garbet," R.W. Harvey, A.W. Hyatt, R.C. Isler, \{ \\ G.L. Jackson, R.A. James, ${ }^{\dagger}$ R.A. Jong, ${ }^{\dagger}$ C.C. Klepper,, M.A. Mahdavi, R. Maingi, $\$$ \\ W.H. Meyer, ${ }^{\dagger}$ R.A. Moyer,, D.G. Nilson, ${ }^{\dagger}$ G.D. Porter, ${ }^{\dagger}$ T.E. Rhodes, ${ }^{\Delta}$ M.J. Schaffer, \\ G.M. Staebler, R.D. Stambaugh, R.E. Stockdale, D.M. Thomas, S. Tugarinov, ${ }^{,}$ \\ M.R. Wade, ${ }^{\mathfrak{E}}$ J.G. Watkins, ${ }^{\bullet}$ W.P. West, and D.G. Whyte
}

This is a preprint of a paper to be presented at the 5th Plasma Edge Theory Meeting, December 4-6, 1995, Asilomar, California and to be published in the Proceedings.

$$
\begin{gathered}
†_{\text {Lawrence Livermore National Laboratory }} \\
\ddagger_{\text {Sandia National Laboratories, Livermore }} \\
\text { Quniversity of California, San Diego } \\
\Delta \text { University of California, Los Angeles } \\
\text { \#CEN-Cadarache, France } \\
\text { EOak Ridge National Laboratory } \\
\text { \$Oak Ridge Associated Universities } \\
\text { TRINITI Laboratory }
\end{gathered}
$$

'Sandia National Laboratories, Albuquerque

INRS-Energie et Materiaux

Work supported by

the U.S. Department of Energy

under Contract Nos. DE-AC03-89ER51114, W-7405-ENG-48, DE-AC05-84OR21400, DE-AC04-94AL85000, and Grant Nos. DE-FG03-86ER53266, DE-FG03-95ER54294

\section{GA PROJECT 3466 \\ FEBRUARY 1996}




\section{DISCLAIMIER}

Portions of this document may be illegible in electronic image products. Imsges are produced from the best available original document. 


\title{
A COMPREHENSIVE 2-D DIVERTOR DATA SET FROM DIII-D FOR EDGE THEORY VALIDATION
}

\author{
by \\ M.E. Fenstermacher, S.L. Allen, D.N. Hill, A.W. Leonard, C.J. Lasnier, T.W. Petrie, \\ R.D. Wood, N.H. Brooks, D.A. Buchenauer, T.N. Carlstrom, J.W. Cuthbertson, \\ E.J. Doyle, T.E. Evans, P.-M. Garbet, R.W. Harvey, A.W. Hyatt, R.C. Isler, \\ G.L. Jackson, R.A. James, R.A. Jong, C.C. Klepper, M.A. Mahdavi, R. Maingi, \\ W.H. Meyer, R.A. Moyer, D.G. Nilson, G.D. Porter, T.E. Rhodes, M.J. Schaffer, \\ G.M. Staebler, R.D. Stambaugh, R.E. Stockdale, D.M. Thomas, S. Tugarinov, \\ M.R. Wade, J.G. Watkins, W.P. West, and D.G. Whyte
}


This report was prepared as an account of work sponsored by an agency of the United States Government. Neither the United States Government nor any agency thereof, nor any of their employees, makes any warranty, express or implied, or assumes any legal liability or responsibility for the accuracy, completeness, or usefulness of any information, apparatus, product, or process disclosed, or represents that its use would not infringe upon privately owned rights. Reference herein to any specific commercial product, process, or service by trade name, trademark, manufacturer, or otherwise, does not necessarily constitute or imply its endorsement, recommendation, or favoring by the United States Government or any agency thereof. The views and opinions of authors expressed herein do not necessarily state or reflect those of the United States Government or any agency thereof. 


\begin{abstract}
A comprehensive set of experiments has been carried out on the DIII-D tokamak to measure the 2-D $(R, Z)$ structure of the divertor plasma in a systematic way using new diagnostics. Measurements cover the divertor radially from inside the X-point to the outer target plate and vertically from the target plate to above the $\mathrm{X}$-point. Identical, repeatable shots were made, each having radial sweeps of the $\mathrm{X}$-point and divertor strike points, to allow complete plasma and radiation profile measurements. Data have been obtained in ohmic, L-mode, ELMing $\mathrm{H}$-mode, and reversed $\mathrm{B}_{\mathrm{T}}$ operation ( $\nabla \mathbf{B}$ drift away from the $\mathrm{X}$-point). In addition, complete measurements were made of radiative divertor plasmas with a Partially Detached Divertor (PDD) induced by $\mathrm{D}_{2}$ injection and with a Radiating Mantle induced by Impurity injection (RMI) using neon and nitrogen. The data set includes first observations of the radial and poloidal profiles of the X-point, inner and outer leg plasmas in PDD and RMI radiative divertor operation. Preliminary data analysis shows that intrinsic impurities play a critical role in determining the SOL and divertor conditions.
\end{abstract}

\title{
1. Introduction
}

The divertor diagnostic set on DIII-D has been upgraded to allow measurements of 2D profiles of electron density, temperature, radiation and impurity content. The data set generated by these diagnostics includes: $n_{e}$ and $T_{e}$ in the divertor from a new Divertor Thomson Scattering system (DTS) [1], $n_{e}$ and $T_{e}$ in the SOL from the outer channels of the core Thomson system, and from target plate and moveable Langmuir probes; $T_{i}$ from Charge Exchange Recombination spectroscopy and a high-resolution visible spectrometer; radiated power from bolometers; and target plate heat and particle flux from Infared TV and probes respectively. Spectroscopy data include 2D images, from tangentially and vertically viewing visible cameras, of $\mathrm{D}_{\alpha}$ light, and of emission from multiple charge states of carbon (the intrinsic impurity) and injected impurities. Line-integrated data is obtained from spatially overlapping visible and VUV spectrometers and from arrays of fast photodiodes. Pressure is measured by gauges in both the SOL and divertor.

In a recent experimental campaign, these diagnostics were used to measure the divertor plasma conditions in ohmic, $\mathrm{L}-$, and ELMing $\mathrm{H}$-mode including reversed toroidal field operation, and radiative divertor plasmas (PDD plasmas induced by $\mathrm{D}_{2}$ puffing and RMI plasmas induced by neon or nitrogen injection). This data set, with supplements to it from campaigns planned for the near future, provides more complete information on the divertor plasma than has been available previously, both for testing edge plasma theories and modeling codes, and for addressing urgent divertor physics R\&D needs for ITER. 


\section{Comprehensive Data Set}

All data obtained in this campaign are from lower single null plasmas $\mathrm{B}_{\mathrm{T}}=2.1 \mathrm{~T}$, $\mathrm{R}=1.69 \mathrm{~m}, \mathrm{a}=0.6 \mathrm{~m}, \mathrm{\kappa} \sim 1.4$. Plasma current ranges from 1.0 MA ( $\mathrm{q}_{95} \sim 6$ ) for some of the ohmic and L-mode data to $1.4 \mathrm{MA}\left(\mathrm{q}_{95}\right.$ 4.4) for the ELMing H-mode, PDD and RMI experiments. Beam power in the L-mode experiments was less than $2 \mathrm{MW}$ to stay below the $\mathrm{H}$-mode power threshold, up to $9 \mathrm{MW}$ in H-, PDD and RMI modes. Helium glow discharge cleaning was used between shots and divertor pumping was not used.

The $2 \mathrm{D}$ profiles of divertor parameters were measured by sweeping the divertor plasma through the line of sight of diagnostics which view the lower region of the vacuum vessel vertically through a port ("V-1") in the vessel floor at $R=1.48 \mathrm{~m}$. The unique plasma control system on DIII-D was used to achieve radial sweeps of the X-point and strikepoints while holding fixed either the $\mathrm{X}$-point height or the outer leg poloidal length from the $X$-point to the outer strikepoint (OSP). Diagnostics which view the divertor region from the $\mathrm{V}-1$ port were used to measure plasma properties from just inside the inner strikepoint (ISP) to well outside the outer strikepoint. The eight channels of DTS measure $n_{e}$ and $T_{e}$ from approximately $1 \mathrm{~cm}$ above to $25 \mathrm{~cm}$ above the target plate (typical $\mathrm{X}$-point height $=20 \mathrm{~cm}$ ). A given point in the divertor is swept over this port at least twice per shot, in a period of $\sim 2 \mathrm{~s}$, so that hysterisis due to the sweep can be monitored; less than $20 \%$ variations in the data were observed. Also, in general, large changes during the sweeps are not observed in the images from the tangentially and vertically viewing, TV cameras which view the entire divertor.

Multiple identical shots with radial sweeps are taken with the spectroscopic diagnostics sequentially tuned to various emission lines. The 2-D images from the visible cameras typically include $\mathrm{D}_{\alpha}, \mathrm{CII}, \mathrm{CIII}$, and CIV data. The spectrometers cover the VUV range $(10-110 \mathrm{~nm})$ and the visible range $(350-800 \mathrm{~nm})$. This documentation has been obtained at several powers in each of the operating modes, with a complete power scan $\left(\mathrm{P}_{\text {inj }}=3.2,4.2,6.5\right.$ and 9.0 MW) in ELMing $\mathrm{H}$-mode plasmas. In addition, a comparison of PDD conditions with a MARFE which forms on a "slow" $(-200 \mathrm{~ms})$ time scale and those with "rapid" ( $\sim 50 \mathrm{~ms})$ MARFE formation is available. These shots show similar large heat flux reduction (factor of 3-5) once the MARFE has formed although the spatial distribution of impurity emission is much more localized near the X-point in the shots with "slow" MARFE formation.

\subsection{Deuterium Plasma Properties}

An initial comparison of ELMing H-mode and PDD divertor plasmas at similar injected powers has been made. In $\mathrm{H}$-mode the DTS measurements show that the radial electron 
temperature in the outer leg near the target plate ranges from 20 to $5 \mathrm{eV}$ (separatrix to the outer SOL) and 70-20 eV near the X-point. When the MARFE forms in PDD operation, the temperature in the entire outer leg drops to the $2-5 \mathrm{eV}$ range (target plate to $\mathrm{X}$-point).

Midplane and outer divertor leg electron presures in $\mathrm{O}, \mathrm{L}-, \mathrm{H}-, \mathrm{PDD}$ and RMI plasmas have been compared [2]. Pressure balance along the SOL is observed (within factor of 2) in $\mathrm{O}, \mathrm{L}-$ and $\mathrm{H}$-modes. With deuterium puffing a PDD is formed in which pressure drops along the separatrix from midplane to target of order $\geq 10 \mathrm{x}$ are seen. The radial density and pressure profiles at the target plate peak outboard of the separatrix (factor of 3-5). In RMI operation, similar poloidal pressure drops near the separatrix are observed although they are less extreme (order $3 \mathrm{x}$ ). Again the temperature in the divertor is fairly uniform and low $(\sim 1-3 \mathrm{eV})$.

\subsection{Intrinsic and Injected Impurities}

The 2-D distribution of intrinsic carbon and $D_{\alpha}$ radiation appears to be similar in $L-$ and ELMing $\mathrm{H}$-modes. In these cases, $\mathrm{D}_{\alpha}$ radiation is predominantly from the vicinity of the ISP with very little emission from the OSP, X-point or either divertor leg. CII radiation peaks near the OSP and near the X-point in the inner SOL, while CIII and CIV emissions are observed predominantly in the inner SOL at the height of the $\mathrm{X}$-point. The distributions change dramatically during PDD and RMI operation. Comparison of ELMing H-mode with PDD plasmas shows that the $\mathrm{D}_{\alpha}$ emission near the ISP is substantially reduced and emission from the outer leg near the OSP increases. The CIII emission shifts from the inner divertor leg to a localized region near the $\mathrm{X}$-point which appears in many cases to be just inside the separatrix. By contrast, the CIV emission shifts from the inner SOL to the entire outer leg from near the OSP to above the X-point inside the separatrix. Correlation of the temporal behavior of the divertor SPRED signal and the tangential TV images confirm that the CIV is distributed along the entire outer leg[4].

\subsection{Radiation and Target Heat Flux}

The 2-D distribution of total radiated power in these experiments is obtained by tomographic reconstruction of two 24 channel bolometer arrays with nearly orthogonal views [3]. In $\mathrm{H}$-mode the peak in radiated power is in a localized region of the inner divertor leg near the X-point. During PDD operation with a MARFE near the X-point, the peak in radiated power shifts to the outer divertor leg near the $\mathrm{X}$-point and substantial radiation is also seen in the entire outer leg down to the target plate. Outer leg radiated power increases a factor of 2-3 while the inner leg radiation drops up to a factor of 2 . Little change in radiation from the core plasma or the SOL above the X-point is seen. In 
contrast, RMI operation with neon injection shows that radiation from a narrow core region just inside the separatrix increases compared with $\mathrm{H}$-mode, and the spatial distribution in the divertor does not change much. Total radiated power coming from the mantle in the core is nearly equal to that coming the divertor.

The divertor peak heat flux is larger at the OSP than at the ISP in O, L- and H-modes. In both PDD and RMI radiative divertor modes, the outer peak heat flux is reduced a factor of 3-5 with little change in the inner heat flux. Total outer target heat flux is reduced by similar factors. In comparisons of $\mathrm{H}$-mode plasmas with oppositely directed toroidal field, little change in the in/out heat flux asymmetry due to changes in the $\nabla \mathbf{B}$ drift direction is observed. This is similar to earlier observations on DIII-D with a more limited set of diagnostics [5].

\section{Summary}

A comprehensive set of $2 \mathrm{D}(\mathrm{R}, \mathrm{Z})$ measurements of divertor properties has been obtained from systematic diverter characterization experiments on DIII-D. Data exist for ohmic, L-mode, ELMing H-mode, and Reversed $\mathrm{B}_{\mathrm{T}}$ operation ( $\nabla \mathbf{B}$ drift away from the $\mathrm{X}$-point). In addition, radiative divertor plasmas with a PDD induced by $\mathrm{D}_{2}$ injection and with a RMI induced by neon and nitrogen injection have been documented. This data set provides substantially more information on the properties of tokamak divertor plasmas than has been available previously. It includes radial and poloidal profiles of electron density and temperature, total radiated power, and emission from multiple lines of intrinsic and injected impurities. Heat flux to the target plates and the plasma conditions at the midplane and at the plates are also measured. In addition the experiments have been organized as much as possible to produce the maximum simultaneous measurements of divertor properties by multiple diagnostics and the most efficient comparisons of plasmas in different operating modes. The present database includes scans of total injected power for most of the operating modes. Future experiments will be done with the goal of adding scans of plasma current, toroidal field (parallel connection length) and X-point height (divertor leg length).

\section{Acknowledgment}

Work supported by U.S. Department of Energy under Contract Nos. DE-AC0389ER51114 (GA), W-7405-ENG-48 (LLNL), DE-AC05-84OR21400 (ORNL), DEAC04-94AL85000 (SNL), and Grant Nos. DE-FG03-86ER53266 and DE-FG0395ER54294. 


\section{References}

[1] Carlstrom, T.N., et. al., Rev. Sci, Instru., 66, 493 (1995); Nilson, D.G., et. al., Toki Conference on Plasma Diagnostics, (1995); Carlstrom, T.N., Nilson, D.G., et. al., submitted to Rev. Sci. Instru., (1995).

[2] Petrie, T.W., et. al., Bull. Am. Phys. S oc., 40, 1832 (1995).

[3] Leonard, A.W., Rev. Sci. Instru., 66, 1201 (1995).

[4] Fenstermacher, M.E., et. al., Bull. Am. Phys. S oc., 40, 1834 (1995).

[5] Allen, S.L. et. al., Plas. Phys. and Contr. Fus., 37, Supplement 11A, A191 (1995). 